\title{
DERIVADO CINAMOÍLICO COM ATIVIDADE NO REPARO DE DNA E OUTRAS SUBSTÂNCIAS DE Cinnamomum australe (LAURACEAE)
}

\author{
Carlos Alberto Carbonezi, Márcia Nasser Lopes, Dulce Helena Siqueira Silva, Ângela Regina Araújo e Vanderlan da \\ Silva Bolzani* \\ Instituto de Química, Universidade Estadual Paulista, CP 355, 14801-970 Araraquara - SP \\ Maria Claudia Marx Young e Marcelo Rogério da Silva
}

Secção de Fisiologia e Bioquímica de Plantas, Instituto de Botânica, CP 4005, 01061-970 São Paulo - SP

Recebido em 17/1/03; aceito em 17/9/03

\begin{abstract}
DNA-DAMAGING ACTIVITY OF A CINNAMATE DERIVATIVE AND FURTHER COMPOUNDS FROM Cinnamomum Australe (LAURACEAE). The bioactive compound trans-3'-methylsulphonylallyl trans-cinnamate (1) along with the inactives iryelliptin (2) and $\left(7 R, 8 S, 1^{\prime} S\right)$ - $\Delta^{8^{\prime}}-3^{\prime}, 5^{\prime}$-dimethoxy-1',4'-dihydro-4'-oxo-7.0.2',8.1'-neolignan (3) were isolated from the leaves of Cinnamomum australe. The structures of these compounds were assigned by analysis of 1D and 2D NMR data and comparison with data registered in the literature for these compounds. The DNA-damaging activity of $\mathbf{1}$ is being described for the first time.
\end{abstract}

Keywords: Cinnamomum australe; Lauraceae; DNA-damaging activity.

\section{INTRODUÇÃO}

As espécies de Lauraceae são conhecidas pelo acúmulo de derivados fenilpropanoídicos, sendo as lignanas e as neolignanas seus principais marcadores químicos ${ }^{1}$. Plantas dessa família são encontradas nas florestas equatoriais e tropicais; na Mata Atlântica, onde sua ocorrência é marcante, são conhecidas popularmente como canela $^{2}$. Na região de Cunha, situada no estado de São Paulo, ainda se encontra Mata Atlântica, de altitude, bastante preservada e, dentre as inúmeras famílias de Angiospermae ali representadas, destacam-se várias espécies de Lauraceae sem nenhum estudo químico e/ou biológico. Como parte de um estudo de bioprospecção com plantas de Cerrado e de Mata Atlântica de São Paulo, espécies desta família foram testadas contra linhagens mutantes de Saccharomyces cerevisiae, objetivando a busca de substâncias com ação na reparação do DNA deficiente-proficiente ${ }^{3}$. Dentre as espécies selecionadas, Cinnamomum australe, coletada na Reserva Ecológica de Cunha, apresentou atividade na reparação do DNA de S. cerevisiae, indicativo de uma atividade antitumoral potencial. Fracionamento bio-guiado do extrato etanólico de $C$. australe levou ao isolamento do derivado bioativo trans-cinamato de trans-3'-metilsulfonilalila (1) juntamente com erieliptina (2) e ( $\left.7 R, 8 S, 1^{\prime} S\right)-\Delta^{8^{\prime}}-3^{\prime}, 5^{\prime}$ '-dimetoxi-1',4'-diidro4'-oxo-7.0.2', 8.1'-neolignana (3). O presente artigo descreve o isolamento, caracterização dos derivados 1-3 e a atividade no reparo de DNA de 1.

\section{PARTE EXPERIMENTAL}

\section{Procedimentos experimentais gerais}

Os espectros de RMN de ${ }^{1} \mathrm{H}$ e de ${ }^{13} \mathrm{C}$ foram registrados em um espectrômetro Bruker DRX-300 operando a 300 e a 76 MHz, respectivamente, utilizando-se $\mathrm{CDCl}_{3}$ como solvente e TMS como referência interna. As constantes de acoplamento $(J)$ foram expressas em Hz. Para a obtenção dos espectros no ultravioleta foi utilizado um equipamento Beckman DU-65. Os espectros de massas foram

*e-mail: bolzaniv@iq.unesp.br<smiles>CS(=O)(=O)/C=C/COC(=O)/C=C/c1ccccc1</smiles><smiles>C=C1OC(=O)C(CCCCc2ccc3c(c2)OCO3)=C1O</smiles>

2<smiles>C=CC=C1C(OC)=C(OC)C(=O)C(OC)=C2[C@H](C)[C@@H](c3ccc4c(c3)OCO4)C12CC=C</smiles>

3

obtidos em espectrômetro FISONS-Modelo VG Plattform II, operando a 70 eV, no modo "electrospray" e em espectrômetro HP5988A Hewlett Packard (quadrupolo), por inserção direta e impacto eletrônico a $70 \mathrm{eV}$. Os espectros no IV foram registrados em aparelho FTIR 1750 Perkin Elmer, na forma de filmes em nujol utilizando janelas de $\mathrm{NaCl}$. Para as cromatografias em coluna utilizou-se sílica gel 60 (0,063-0,200 mm e 0,230-0,400 mm, Merck) e Sephadex LH-20 (Sigma). Nas cromatografias em placa utilizou-se sílica gel $60 \mathrm{GF}_{254}$ e $\mathrm{PF}_{254}$ (Merck). As placas foram observadas sob luz UV 254-366 nm e reveladas com vapores de iodo ressublimado ou solução de $\mathrm{H}_{2} \mathrm{SO}_{4}$ /EtOH (anidro) 1:1, seguida de aquecimento.

\section{Material vegetal}

Folhas de Cinnamomum australe Walt. foram coletadas na Reserva Ecológica de Cunha, São Paulo, em maio de 2000. O material 
foi identificado pela Dra. I. Cordeiro, Curadora do Herbário do Instituto de Botânica de São Paulo, SP; uma exsicata encontra-se aí depositada, sob o $\mathrm{n}^{\circ}$. Cord 1203.

\section{Extração e fracionamento}

As folhas de $C$. australe $(650 \mathrm{~g})$, secas e moídas, foram extraídas com metanol a frio (3 L). O extrato alcoólico foi evaporado completamente e uma alíquota deste extrato foi submetida ao bioensaio, indicando atividade moderada. $\mathrm{O}$ extrato foi dissolvido em metanolágua $(80 \%)$ e, em seguida, submetido a sucessivas partições com $800 \mathrm{~mL}$ de solventes de diferentes polaridades, fornecendo as frações hexânica $(3,0 \mathrm{~g})$, diclorometânica $(9,8 \mathrm{~g})$ e em acetato de etila $(4,5 \mathrm{~g})$. A fração diclorometânica bioativa foi cromatografada em coluna de sílica gel $(5 \times 50 \mathrm{~cm}, 400 \mathrm{~g})$ utilizando-se misturas de hexano/AcOEt, com aumento de polaridade $(1: 1,1: 2,2: 3)$, fornecendo 14 frações de $300 \mathrm{~mL}$. Todas as frações foram submetidas ao bioensaio com $S$. cerevisiae e as frações 10-14, bioativas, foram escolhidas para fracionamento e purificação. Estas frações, após análise usual por cromatografia em camada delgada comparativa (CCDC), foram reunidas F-10-14 (102 mg) e, em seguida, o material resultante desta reunião foi submetido a uma filtração em gel de Sephadex LH-20, utilizando-se uma mistura de diclorometano-metanol (4:1, $1: 1$ e $1: 4)$ e metanol. Deste procedimento foram coletadas seis frações (F-1 a F-6), das quais F-5 (38,0 mg) e F-6 (12,0 mg) mantiveram a atividade. A purificação da fração F-5 foi realizada em coluna cromatográfica de $\mathrm{Si}$ gel $(1 \times 30 \mathrm{~cm})$, eluída com misturas de $\mathrm{CHCl}_{3} /$ $\mathrm{MeOH}$ com aumento gradual de polaridade. Foram recolhidas frações de $3 \mathrm{~mL}$, agrupadas posteriormente em dez frações, de acordo com o perfil cromatográfico monitorado por CCDC. Das duas primeiras frações resultantes deste procedimento, foram isoladas as substâncias 1 (3,2 mg) e $\mathbf{2}$ (16,0 mg). Análise por cromatografia por CCDC, das demais frações impuras, revelou que a F-5-8 era constituída de dois componentes. Esta mistura foi lavada várias vezes com acetona e o sólido remanescente foi purificado por recristalização em $\mathrm{CCl}_{4}$, fornecendo a substância 3 (8 mg). A fração F-6, após lavagem com éter e recristalização em EtOH, apresentou-se como um sólido cristalino com ponto de fusão $98-99{ }^{\circ} \mathrm{C}$ e foi também identificada como 1.

trans-cinamato de trans-3'-metilsulfonilalila (1): Cristais, P. F. $=98-99{ }^{\circ} \mathrm{C}$ (lit. ${ }^{4} 97-98{ }^{\circ} \mathrm{C}$, em EtOH). IV, $v^{\mathrm{KBr}}{ }_{\max } \mathrm{cm}^{-1}: 1700,1637$, $1570,1300,1127,780 . \mathrm{UV}, \lambda^{\mathrm{MeOH}}{ }_{\max } \mathrm{nm}(\log \varepsilon) 279$ (4.30), $224(4.0)$, EM m/z (rel. int.) 266 (50), 187 (35), 131 (100) 103(54); análise elementar (\%): $\mathrm{C}=58,6, \mathrm{H}=5,2, \mathrm{O}=12,02, \mathrm{~S}=24,0$ correspondendo à fórmula molecular $\mathrm{C}_{13} \mathrm{H}_{14} \mathrm{O}_{4} \mathrm{~S}$. Dados de $\mathrm{RMN}$ de ${ }^{1} \mathrm{H},{ }^{13} \mathrm{C}, \mathrm{COSY} \mathrm{e}$ HMBC, ver Tabela 1.

irieliptina (2) Cristais, P. F. $=82-84{ }^{\circ} \mathrm{C}, \mathrm{CCl}_{4}\left(\right.$ lit $^{5} 81-83{ }^{\circ} \mathrm{C}$, em $\mathrm{C}_{6} \mathrm{H}_{6}$ ). Dados espectrométricos idênticos aos descritos na literatura ${ }^{5}$.

(7R, 8S, 1'S)- $\Delta^{8}$ '-3',5'-dimetoxi-1',4'-diidro-4'-oxo-7.0.2', 8.1' 'neolignana (3): Cristais, P. F. $=137-139{ }^{\circ} \mathrm{C}$, similar ao descrito na literatura ${ }^{6}$. Dados espectroscópicos idênticos aos publicados anteriormente para esta substância ${ }^{6}$.

\section{Bioensaio}

O teste preliminar para avaliação da atividade sobre as vias de reparo e/ou recombinação do DNA foi realizado de acordo com metodologia e protocolos bem estabelecidos ${ }^{3}$. Este ensaio foi desenvolvido com base na constatação de que a maioria das células tumorais têm falhas em sua capacidade de reparar danos no DNA quando comparadas com as células normais, sugerindo que agentes com toxidez seletiva para células deficientes no reparo do DNA poderiam ser agentes anticancerígenos potenciais. Confirmando este raciocínio foi de-
Tabela 1. Dados de RMN de ${ }^{1} \mathrm{H}$ e de ${ }^{13} \mathrm{C}$ para o trans-cinamato de trans-3'-metilsulfonilalila (1)

\begin{tabular}{|c|c|c|c|c|}
\hline Posição & $\delta_{\mathrm{C}}$ & $\delta_{\mathrm{H}}$ & COSY & $\begin{array}{l}\mathrm{HMBC} \\
(\mathrm{H} \rightarrow \mathrm{C})\end{array}$ \\
\hline 1 & 135,0 & - & - & - \\
\hline 2 & 129,0 & $7,42 \mathrm{~m}$ & - & $\mathrm{C}-1, \mathrm{C}-4$ \\
\hline 3 & 129,9 & $7,42 \mathrm{~m}$ & - & $\mathrm{C}-1, \mathrm{C}-4$ \\
\hline 4 & 131,3 & $7,42 \mathrm{~m}$ & - & $\mathrm{C}-2$ \\
\hline 5 & 129,9 & $7,42 \mathrm{~m}$ & - & $\mathrm{C}-1$ \\
\hline 6 & 129,0 & $7,42 \mathrm{~m}$ & - & C-1, C-2 \\
\hline 7 & 146,2 & $7,76 \mathrm{~d}(16,0)$ & H-8 & C-9. C-1, C- \\
\hline \multicolumn{5}{|l|}{2} \\
\hline 8 & 117,9 & $6,46 \mathrm{~d}(16,0)$ & H-7 & $\mathrm{C}-1, \mathrm{C}-2, \mathrm{C}-$ \\
\hline \multicolumn{5}{|c|}{ 年 } \\
\hline 9 & 166,0 & - & - & - \\
\hline $1^{\prime}$ & 62,2 & $4,95 \mathrm{dd}(1,0 ; 3,0)$ & H-2' & C-9, C-3' \\
\hline $2^{\prime}$ & 141,2 & $7,01 \mathrm{dt}(3,0 ; 16,0)$ & H-1', H-3' & C-1', C-2' \\
\hline $3^{\prime}$ & 130,5 & $6,65 \mathrm{dt}(1,0 ; 16,0)$ & $\mathrm{H}-2$ & $\begin{array}{l}\mathrm{C}-1^{\prime}, \mathrm{C}-2 \text { ', } \\
\mathrm{CH}_{3}\end{array}$ \\
\hline$-\mathrm{CH}_{3}$ & 42,5 & $2,89 \mathrm{~s}$ & - & $\mathrm{C}-3^{3}$ \\
\hline
\end{tabular}

Espectros registrados em $\mathrm{CDCl}_{3},(300 \mathrm{MHz}$ para hidrogênio e 75 $\mathrm{MHz}$ para carbono), deslocamentos químicos $(\delta)$ usando-se como padrão TMS. Atribuições feitas com base nos experimentos de DEPT 135 e HMQC.

monstrado que leveduras mutantes com esta deficiência são hipersensíveis à maioria dos agentes que causam dano ao $\mathrm{DNA}^{7}$. Dessa forma, a interpretação dos resultados deste bioensaio está fundamentada na resposta diferencial entre uma levedura com células normais, capazes de fazer reparos no DNA ( $\operatorname{Rad}+)$, e células que não são capazes de reconstruir a seqüência do DNA $(\operatorname{Rad} 52 \mathrm{Y})$, frente a uma determinada amostra (extrato bruto, fração e/ou substância pura). A linhagem Rad+ é definida como o tipo selvagem, enquanto Rad 52Y é a linhagem mutante produzida a partir de Rad+, apresentando deficiências relacionadas com uma das três maiores vias de reparo do DNA em leveduras. Rad 52 Y está associada ao reparo recombinacional do DNA, ou seja, apresenta deficiências na recombinação mitótica (na conversão e "crossing over") e na recombinação meiótica. O ensaio é conduzido pela medida do halo de inibição do crescimento das células deficientes $(\operatorname{Rad} 52 \mathrm{Y})$, em comparação com as células tipo selvagem Rad+ (proficientes nas vias de reparo do DNA) e com o controle positivo camptotecina. Os resultados são expressos como valores de $\mathrm{CI}_{12}$, concentração da amostra $(\mu \mathrm{g} / \mathrm{mL})$ requerida para produzir um halo de inibição de $12 \mathrm{~mm}$ de diâmetro, ao redor de uma cavidade de $100 \mu \mathrm{L}$, após um período de incubação de $48 \mathrm{~h}$, a $30^{\circ} \mathrm{C}$.

Os ensaios foram feitos em triplicata e em diferentes concentrações para os extratos $(4000,2000,1000$ e $500 \mu \mathrm{g} / \mathrm{mL})$ e substâncias puras $(500,200,100$ e $50 \mu \mathrm{g} / \mathrm{mL})$. Os valores de $\mathrm{CI}_{12}$ foram determinados das curvas de dose-resposta (log da concentração da amostra em $\mu \mathrm{g} / \mathrm{mL} v s$. valor médio do diâmetro do halo de inibição, em mm).

Uma amostra é considerada ativa quando a $\mathrm{CI}_{12}$ obtida para a levedura mutante é três vezes menor que a $\mathrm{CI}_{12}$ obtida para a levedura normal $(\mathrm{Rad}+)$ e menor que $2000 \mu \mathrm{g} / \mathrm{mL}$, para extratos, ou 200 $\mu \mathrm{g} / \mathrm{mL}$, para substâncias puras.

\section{RESULTADOS E DISCUSSÃO}

O extrato etanólico das folhas de $C$. australe apresentou atividade seletiva sobre a cepa mutante de $S$. cerevisiae, $\operatorname{Rad} 52$ Y (Tabela 2). A fração diclorometânica proveniente da partição líquido/líquido deste extrato manteve a atividade e, após os procedimentos usuais de fracionamento e purificação, forneceu os constituintes 1-3. 
Tabela 2. Valores de $\mathrm{CI}_{12}(\mu \mathrm{g} / \mathrm{mL})$ obtidos a partir dos ensaios com as linhagens $\operatorname{Rad}+$ e $\operatorname{Rad} 52 \mathrm{Y}$ de $S$. cerevisiae

\begin{tabular}{|c|c|c|}
\hline \multirow[t]{2}{*}{ Amostras } & \multicolumn{2}{|c|}{ Linhagens mutantes de $S$. cerevisiae* } \\
\hline & Rad+ & $\operatorname{Rad} 52 \mathrm{Y}$ \\
\hline Extrato EtOH & $>1000$ & 600 \\
\hline Fração $\mathrm{CH}_{2} \mathrm{Cl}_{2}$ & $>1000$ & 500 \\
\hline 1 & $>500$ & 100 \\
\hline 2 & $>500$ & $>500$ \\
\hline 3 & $>500$ & $>500$ \\
\hline Camptotecina & 20 & 5 \\
\hline
\end{tabular}

* Concentração inicial do teste com substâncias puras 500 Mg/mL).

O espectro de massas, obtido pela técnica "electrospray", do derivado bioativo 1 apresentou um íon molecular $[\mathrm{M}+\mathrm{Na}]^{+} \mathrm{m} / \mathrm{z}, 289$ e os íons fragmentários $m / z, 210,154$ e 126 atribuídos a $\left[\mathrm{M}+\mathrm{Na}^{+}\right.$$\left.\mathrm{MeSO}_{2}\right]$, uma unidade cinamoíloxi $\left[\mathrm{C}_{9} \mathrm{H}_{7} \mathrm{O}+\mathrm{Na}^{+}\right]$e ao fragmento resultante da perda de $\mathrm{CO}$ da unidade cinamoíloxi $\left[\mathrm{C}_{8} \mathrm{H}_{8}+\mathrm{Na}\right]$, respectivamente. Os dados obtidos de seus espectros de RMN de ${ }^{1} \mathrm{H}$ e de ${ }^{13} \mathrm{C}$ (Tabela 1) indicaram claramente que uma parte da estrutura de $\mathbf{1}$ é formada por um grupo cinamoílico, confirmando a análise do espectro de massas. Análise detalhada dos dados de RMN indicou que a unidade que está ligada à parte cinamoílica corresponde a um sistema trans-1,2-dissubstituído, evidenciado pelos sinais em $\delta 4,95$ dd $(J=1,0 ; 3,0 \mathrm{~Hz}), \delta 7,01 \mathrm{dt}(J=3,0 ; 16,0 \mathrm{~Hz})$ e $6,65 \mathrm{dt}(J=16,0$; $1,0 \mathrm{~Hz}$ ) e pelo sinal em $\delta 2,89$ (s) referente a um grupo metílico. Estes dados, analisados em conjunto com aqueles obtidos do espectro de massas, análise elementar e comparação com a literatura ${ }^{4,8}$ permitiram concluir que $\mathbf{1}$ é a substância conhecida trans-cinamato de trans-3'-metilsulfonilalila. Em adição, as análises dos dados espectrais de $\mathrm{RMN}$ de ${ }^{13} \mathrm{C}$ e de HMBC permitiram atribuir de maneira inequívoca os valores dos deslocamentos químicos dos carbonos 4 e 3' dessa substância (Tabela 1) uma vez que, no único registro encontrado na literatura ${ }^{4}$, esses valores foram obtidos por técnicas unidimensionais que não permitiram sua discriminação. Este é o terceiro registro do isolamento dessa substância e destaca-se que os registros anteriores foram também de espécies de Lauraceae (Cinnamomum triplinervis ${ }^{8}$ e Phoebe brenesii ${ }^{4}$ ).

Os dados de $\mathrm{RMN}$ de ${ }^{1} \mathrm{H}$ e de ${ }^{13} \mathrm{C}$ para irieliptina ${ }^{5}(2)$ indicaram tratar-se de um derivado do ácido tetrônico, já conhecido como um dos constituintes químicos isolados de Iryanthera elliptica Ducke 5 . A estrutura da substância 3 foi elucidada a partir de seus dados espectrais de $\mathrm{RMN}$ de ${ }^{1} \mathrm{H}$ e de ${ }^{13} \mathrm{C}$ que demonstraram tratar-se da neolignana $\left(7 R, 8 S, 1^{\prime} S\right)-\Delta^{8}$ '-3', 5' -dimetoxi-1',4'-diidro-4' -oxo-
7.0.2', 8.1'-neolignana já descrita na literatura como constituinte de Ocotea catharinensis ${ }^{6}$, uma Lauraceae comum na Mata Atlântica, conhecida vulgarmente como "canela preta".

$\mathrm{O}$ derivado cinamoílico $\mathbf{1}$ mostrou atividade moderada $\left(\mathrm{CI}_{12}\right.$ $100 \mu \mathrm{g} / \mathrm{mL}$ ), em comparação com o agente anticancerígeno camptotecina $\left(\mathrm{CI}_{12} 5 \mu \mathrm{g} / \mathrm{mL}\right)$, porém seletiva contra a linhagem Rad 52Y (Tabela 2) enquanto que $\mathbf{2}$ e $\mathbf{3}$ mostraram-se inativos na dosagem testada $(500 \mu \mathrm{g} / \mathrm{mL})$. Este dado é de grande interesse porque indica que a substância $1\left(\mathrm{CI}_{12} 100 \mu \mathrm{g} / \mathrm{mL}\right)$ tem especificidade sobre as células deficientes nos mecanismos de reparo do DNA (Rad 52Y), inibindo o seu crescimento, mas atua muito pouco sobre o crescimento das células normais $\left(\mathrm{CI}_{12}>500 \mu \mathrm{g} / \mathrm{mL}\right)$, proficientes no reparo do (DNA Rad+). Essa característica é fundamental quando o interesse é a busca de agentes anticancerígenos, pois o que se deseja é a seleção de candidatos que sejam tóxicos para as células tumorais ou deficientes ( $\operatorname{Rad} 52 \mathrm{Y})$, impedindo a sua proliferação, mas que sejam inativos, ou atuem muito pouco, sobre o crescimento das células sadias $(\operatorname{Rad}+)$.

Esse é o primeiro registro na literatura dessa classe de substância, com atividade em $S$. cerevisiae geneticamente modificada (deficiência relacionada com uma das maiores vias de reparação do DNA) ${ }^{3}$. Substâncias com essa ação citotóxica seletiva nas células deficientes no reparo do DNA podem agir como um agente antitumoral potencial.

\section{AGRADECIMENTOS}

Os autores agradecem à FAPESP, programa Biota-FAPESP (Instituto Virtual da Biodiversidade, www.biota.org) e ao CNPq, pelo apoio financeiro e pelas bolsas concedidas a V. da S. Bolzani e M. C. M. Young.

\section{REFERÊNCIAS}

1. Gottlieb, O. R.; Yoshida, M. Em Natural Product of Wood Plants; Rowe, J. W., ed.; Springer-Verlag: Berlin, 1989, p. 439-511.

2. Pedralli, G.; Dissertação de Mestrado, Universidade Estadual Paulista, Brasil, 1982.

3. Gunatilaka, A. A. L.; Kingston, D. G. I.; Johnson, R. K.; Pure Appl. Chem. 1994, 66, 68 .

4. Castro, O.; Lopez, J.; Vergara, A.; J. Nat. Prod. 1985, 48, 640.

5. Braz Filho, R.; Diaz, D. P. P.; Gottlieb, O. R.; Phytochemistry 1980, 19, 455.

6. Haraguchi, M.; Motidome, M.; Yoshida, M.; Gottlieb, O. R.; Phytochemistry 1983, 22, 561.

7. Eng, W-K.; Faucette, L.; Johnson, R. K.; Stenglanz, R.; Mol. Pharmacol. 1988, 34, 775

8. Ripperger, H.; Diaz, M.; Schreiber, K. ; Phytochemistry 1981, 20, 1453. 